\title{
Interactive Thresholding of Central Acuity under Contrast and Luminance Conditions Mimicking Real World Environments: 1. Evaluation against LogMAR Charts
}

\author{
Walter Gutstein ${ }^{1,4}$, Stephen H Sinclair ${ }^{2}$, Peter Presti ${ }^{3}$ and Rachel V North ${ }^{4}$
}

${ }^{1}$ Pennsylvania College of Optometry, Salus University, 8360 Old York Rd, Elkins Park, PA 19027, Unites States of America ${ }^{2}$ Hahnemann School of Medicine, Drexel University, 200 E. State Street, Suite 301, Media, PA 19063, Unites States of America 3Interactive Multi-Media Center, Georgia Institute of Technology, TSRB Building Room 314B, 85 5th Street NW, Atlanta, GA 30308, Unites States of America ${ }^{4}$ School of Optometry \& Vision Sciences, Cardiff University, Maindy Road, Cardiff,CF24 4LU, United Kingdom

\begin{abstract}
Purpose: The Central Vision Analyzer (CVA) is an interactive, automated computer device that rapidly thresholds central acuity under conditions mimicking customary photopic and mesopic activities. In sequence, the CVA may test up to 6 environments, and in this series was used to test 3 mesopic environments $(98 \%$ and $50 \%$ MC against $1.6 \mathrm{~cd} / \mathrm{m}^{2}$ background, $25 \% \mathrm{MC}$ against $\left.5 \mathrm{~cd} / \mathrm{m}^{2}\right)$, then 3 glare environments $(98 \%, 10 \%$ and $8 \% \mathrm{MC}$, against 200 $\mathrm{cd} / \mathrm{m}^{2}$ background). This report compares the CVA thresholded acuity with that measured utilizing standard letter acuity charts.
\end{abstract}

Methods: In 481 normal eyes acuity was measured with best spectacle and contact lens refraction using both CVA and 0.1 logMAR ETDRS charts presenting similar contrast and luminance. In addition for 162 emmetropic, eyes, acuity was tested with a $15 \%$ MC chart placed outdoors with sun overhead and with sun at $15^{\circ}$ off-axis and compared with the CVA thresholded acuity at $10 \%$ and $8 \%$ MC presented in a darkened room.

Results: All CVA modules demonstrated high Pearson correlation coefficients ( $r=0.51$ to $r=0.94, p<0.01$ ), Bland and Altman statistical similarity with the acuity measured from similar contrast charts as well as between the acuity measured with a $15 \% \mathrm{MC}$ letter chart with the sun overhead and CVA $10 \%$ glare module and between acuity with a $15 \% \mathrm{MC}$ chart viewed with the sun $15^{\circ}$ off-axis and that with CVA $8 \%$ glare module presented in the darkened room.

Conclusions: The CVA demonstrates the ability to accurately threshold the acuity of normal eyes compared with chart acuity under conditions of contrast, luminance and fixation times simulating normal photopic and mesopic activities and appears to provide the clinician rapidly with a better understanding of visual function under a variety of day and evening tasks.

Keywords: Central vision analyzer; Correlation coefficients; Eye

\section{Introduction}

The measurement of vision utilizing charts in the clinic is most often done with one chart using one or a minimal set of contrasts of black letters or gratings that are presented against a white background of one luminance and in a single, moderate photopic environment represented by the examination lane. However, the results of chart testing have been shown not to scale reliability with activities of daily living in other contrast or luminance environments $[1,2]$ or to correlate with performance in tasks such as reading [3-6] or driving [7]. Although there are charts commercially available that present reduced contrast letters or sinusoidal gratings against a photopic standard background illumination, often presented with focal glare sources, or at reduced luminance such as the Smith-Kettelwell SKILL card [8], nevertheless, severe criticism has been raised about their thresholding endpoints $[9,10]$ and their ability in the clinic to define the visual function of the patient under the extremely variable real world mesopic or photopic environments with or without glare. Furthermore, the 1 to 4 second fixations that are usually allowed for chart testing do not mimic fixations that are typically required for daily activities (e.g. driving, facial recognition, or reading [11-14], and chart testing is biased by the termination criteria by the examiner and by whether the examiner had access to the results of prior testing $[15,16]$. Measuring acuity with a chart, therefore, most often does not enable the physician to understand and treat the failings (and complaints) of the patient. In order to understand the vision problems in eyes with pathology, a vision test that mimics real world visual task requirements is desperately needed [17-21].
The Central Vision Analyzer (CVA, Sinclair Technologies, Media, $\mathrm{Pa}$ ), is a clinical device that rapidly measures central acuity under contrast and luminance conditions that simulate real world environments encountered during routine day and evening activities and presented at durations that mimic the visual fixations required during those tasks. The CVA utilizes an interactive computer program that presents a fixation cross against which Landolt C's are flashed for $250 \mathrm{msec}$ (similar to fixation times measured in common activities $[15,16])$, centered on a cross against a background pedestal that precedes the $\mathrm{C}$ presentation by $300 \mathrm{msec}$ in order to prevent retinal adaptive persistence of the fixation cross. At each presentation the $\mathrm{C}$ is tumbled one of four positions; within 4 seconds the patient must respond his or her recognition of the correct position by pressing one of 4 buttons on a response pad (Figure 1). Beginning at 20/100 and based on the responses, the program enlarges or contracts the $\mathrm{C}$ in a reversing

*Corresponding author: Stephen $\mathrm{H}$ Sinclair, , Hahnemann School of Medicine Drexel University, 230 N. Broad Street, Philadelphia, PA 19102, USA, Tel: 610892-1708; Fax: 610-892-8766; E-mail: ssinclair@stephensinclairmd.com

Received May 04, 2015; Accepted June 20, 2015; Published June 22, 2015

Citation: Gutstein W, Sinclair SH, Presti P, North RV (2015) Interactive Thresholding of Central Acuity under Contrast and Luminance Conditions Mimicking Real World Environments: 1. Evaluation against LogMAR Charts. J Comput Sci Syst Biol 8 225-232. doi:10.4172/jcsb.1000193

Copyright: (c) 2015 Gutstein W, et al. This is an open-access article distributed under the terms of the Creative Commons Attribution License, which permits unrestricted use, distribution, and reproduction in any medium, provided the original author and source are credited. 


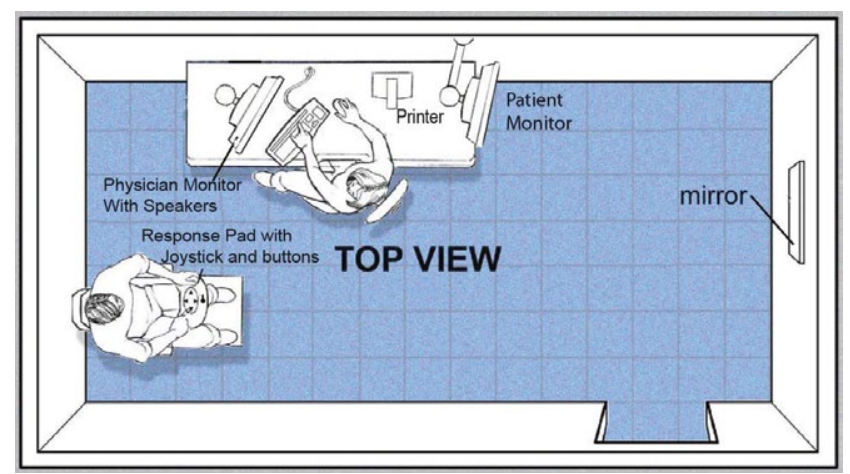

Figure 1: Patient with response pad that contains buttons in a diamond allowing response to the tumbled $\mathrm{C}$ position presented on the monitor when viewed in a mirror at the opposite end of the room (not shown).

staircase with progressively diminishing steps (6:4:2:1 of logMAR 0.05 steps) until a threshold is reached, determined by two correct responses at the lowest $\log$ MAR 0.05 presentation with two incorrect responses at one logMAR 0.05 step smaller. This thresholding method represents a derivation of the more elaborate PEST $[17,18]$ ) and probit analysis methods balancing the requirements of clinical expediency (requiring less than 1-2 minutes for testing an eye under as many as 6 different contrast and luminance conditions) and an accuracy approaching the true threshold of psychophysical testing within approximately $3.5 \%$ of that determined by the PEST threshold when conducted under similar conditions (PEST [22,23]). As noted, several modules of different luminance and contrast conditions may be selected for testing an eye during a single testing session; the testing conditions for each CVA module that were utilized in this study are reported under the Materials section.

Prior reports conducted with the CVA have demonstrated significant vision abnormalities associated with a number of ocular pathologies in spite of good acuity measured with a high contrast chart and certainly verify the value of such testing toward understanding patient complaints [24-27]. The study reported here attempts to provide validation of the CVA by examining the CVA acuities measured in normal eyes compared with acuities measured using letter charts that present similar luminance and contrast conditions as well as utilizing charts placed in photopic situations with sun glare. The details of the CVA modules and charts utilized in this study are presented in the Materials section.

\section{Materials Utilized for the Study}

For this study, the CVA in sequential fashion was designed to measure vision first in 3 mesopic and then 3 photopic, glare environments; the contrast and luminance levels are presented in Table 1a. Together with the relative dark background of the instruction animations and practice test, this allows approximately 1.5 minutes for the subject to adapt to the mesopic luminance levels before testing commences. The testing begins with $98 \% \mathrm{MC}$ white, Landolt C's presented against a $1.6 \mathrm{~cd} / \mathrm{m}^{2}$ background to define the optimal acuity as this has been shown in a number of studies to be better than with the typical black letters against a white field [28-31]. The letter contrast presentation for each of the subsequent mesopic modules was chosen after defining the vision tasks for each activity, following the general outlines of Johnson [32] (in these two cases, restaurant dining and driving at dusk). Camera RAW images were taken from the observer's perspective of several scenes representing the vision tasks of an activity with a Gretagmacbeth color contrast gradation card (Xrite, Grand Rapids, Mi), placed perpendicular to the camera angle in the scene to provide a standard of contrasts against which the visual task elements were measured. Sufficient bracketing images were taken to provide a linear range of luminance for all components within 60 degrees of the fixated targets. From the RAW images, and direct luminance measurements of the Gretagmacbeth card, the CIE color space contrasts were calculated for each element and adjacent background (defined by the corrected Euclidean distance between the two points in $\mathrm{L}^{\star} \mathrm{a}^{\star} \mathrm{b}^{\star}$ color space, divided by the maximum luminance, $\left.\Delta \mathrm{E} / \mathrm{L}^{\star}\right)[33,34]$ representing a derivation of the local, band-limited contrast evaluation devised by Pelli [35]. The components of each vision task associated with an activity (for example facial recognition and menu reading, among others for the activity restaurant dining) were ordered according to weighting of the subjective importance defined by participants of the activity (in each case no fewer than 10 persons), and then examined to define those that required the finest resolution among the higher ranked. The average of these $\Delta \mathrm{E} / \mathrm{L}^{*}$ contrasts was utilized to create the contrast of the gray Landolt $\mathrm{C}$ flashed against the average of the background luminance.

The effect of glare from light sources within the environment was evaluated by calculating the luminance (from the bracketed images) and the angular distance from the fixated targets of each light source. The data of Vos [36] was used to calculate the influence of the off-axis veiling glare on the reduction in perceived contrast for a 30-yearold individual, and this adjusted contrast was used for the presented Landolt C. Integration was performed for extended light sources (such as windows that back lit the fixation elements) as per Vos [36].

The photopic/glare modules first present Landolt C's at $98 \%$ MC against $200 \mathrm{~cd} / \mathrm{m}^{2}$, chosen to compare with the measured acuity obtained using the same high contrast, ETDRS, logMAR chart, although the room luminance during testing $\left(<3 \mathrm{~cd} / \mathrm{m}^{2}\right)$ is less than the $85 \mathrm{Cd} /$ $\mathrm{m}^{2}$ recommended [37]. For the additional two modules, contrasts that are encountered while playing golf and tennis in sun environments were evaluated in the same fashion as above using bracketed camera RAW images. However, we recognize that standard monitors cannot possibly present the luminance of sunlit environments. Therefore, the effect of glare was evaluated by altering the contrasts according to Vos [36] assuming a sun luminance of $20,000 \mathrm{~cd} / \mathrm{m}^{2}$. The contrasts of the finer resolution tasks when playing tennis or golf averaged 15\% MC. For a 30 year-old individual playing with the sun overhead but slightly forward of the subject, this is equivalent to visualizing a $10 \% \mathrm{MC}$ target, and with the sun at $15^{\circ}$ off-axis, an $8 \% \mathrm{MC}$ target [36]. CVA testing with these resultant contrasts should approximate the acuity measured under those glare conditions allowing comparison of the subject's acuity with that of a 30 year-old.

In the study reported here, the acuity was measured in all eyes utilizing the CVA 6 modules discussed above presented on a monitor in a room darkened to less than $5 \mathrm{~cd} / \mathrm{M}^{2}$ and was also measured with a series of 6 ETDRS design, Sloane letter, 0.1 logMAR charts [37] back-lit in a standard $85 \mathrm{~cd} / \mathrm{m}^{2}$ illuminated cabinet (PrecisionVision, La Salle, IL) and presented in the same darkened room. The charts presented gray-black letters at a luminance and Michelson contrast that matched each CVA module and were in the same order as the CVA module testing. For the mesopic modules, the luminance of the letters of each chart was reduced to match that of the CVA respective module by using neutral density filters (Sapsis Rigging, Landowsne, Pa) placed 


\begin{tabular}{|c|c|c|c|c|c|c|}
\hline S.no & CVA modules & $\begin{array}{l}\text { MC Michelson } \\
\text { Contrast }\end{array}$ & Letter & $\begin{array}{l}\text { Letter luminance } \\
\mathrm{cd} / \mathrm{m}^{2}\end{array}$ & \begin{tabular}{c|c} 
Background \\
luminance $\mathrm{cd} / \mathrm{m}^{2}$
\end{tabular} & Test simulates \\
\hline 1 & CVA 98\% Mes. & $98 \%$ & White & 220 & 1.6 & Mesopic - high contrast \\
\hline 2 & CVA $25 \%$ Mes. & $25 \%$ & Grey & 8.4 & 5 & Mesopic - restaurant dining \\
\hline 3 & CVA $50 \%$ Mes. & $50 \%$ & Grey & 4.8 & 1.6 & Mesopic - driving at dusk \\
\hline 4 & CVA 98\% Pho. & $98 \%$ & Black & 1.6 & 220 & Photopic -high contrast \\
\hline 5 & CVA $10 \%$ Glare & $10 \%$ & Grey & 180 & 220 & Photopic glare - golf, sun over head \\
\hline 6 & CVA 8\% Glare & $8 \%$ & Grey & 186 & 220 & Photopic glare - golf, sun $15^{\circ}$ off-axis \\
\hline S.no & Chart tests & $\begin{array}{l}\text { MC Michelson } \\
\text { Contrast }\end{array}$ & Letter & $\begin{array}{c}\text { Letter } \\
\text { luminance } \mathrm{cd} / \mathrm{m}^{2}\end{array}$ & $\begin{array}{l}\text { Background } \\
\text { luminance } \mathrm{cd} / \mathrm{m}^{2}\end{array}$ & Test simulates \\
\hline 1 & ETDRS $97 \%$ & $97 \%$ & Black & 1.6 & 100 & Mesopic - high contrast \\
\hline 2 & ETDRS $25 \%$ & $25 \%$ & Grey & 8.5 & 5.1 & Mesopic - restaurant dining \\
\hline 3 & ETDRS $50 \%$ & $50 \%$ & Grey & 1.6 & 4.8 & Mesopic - driving at dusk \\
\hline 4 & ETDRS $10 \%$ & $10 \%$ & Grey & 81 & 100 & Photopic - golf, sun overhead \\
\hline 5 & ETDRS 8\% & $8 \%$ & Grey & 85 & 100 & Photopic - golf, sun $15^{\circ}$ off-axis \\
\hline
\end{tabular}

Tables 1a and1b: The order of a) CVA module testing and b) ETDRS chart testing is presented with the letter and background luminance for each test. MC=Michelson Contrast, $\mathrm{cd} / \mathrm{m}^{2}=$ Candelas per meter squared.

in front of the chart. The luminance and contrasts (Tables 1a and 1b) were verified by spot photometer readings (Sekonic L558, Sekonic Industries). The CVA monitor luminance and $\mathrm{C}$ contrasts were controlled using monthly colorimeter recalibration (Huey Pantone, Carlstadt, NJ).

\section{Patients and methods}

This research adhered to the tenets of the Declaration of Helsinki, and IRB approval was obtained. Subjects were recruited above 18 years of age; all persons signed informed consent. Normal eyes were included as defined by a negative ocular or systemic history and a normal ocular examination utilizing $90 \mathrm{D}$ biomicroscopy to examine the fundus without pupil dilation. The refractive error was within \pm 5.00 diopters with astigmatism $\leq 1.00 \mathrm{D}$ and with a difference between eyes of astigmatism $\leq 0.50 \mathrm{D}$ and spherical equivalent $\leq 1.00 \mathrm{D}$. The LOCS III [38] graded lens opacity was $\leq \mathrm{NO} 1, \mathrm{NC} 1$ for ages $15-50, \leq \mathrm{NO}$, NC2 for ages 51-65, and without cortical or PSC opacity observed within the pupil under dim light. Eyes were excluded if a corneal surface irregularity was detected felt to impact vision by producing an aberration of more than $0.4 \mathrm{~mm}$ corneal radius curvature. Tear film stability was assessed using tear break-up times [39] with $\geq 10$ seconds considered normal. The surface of the contact lens was assessed for deposits, wetting and fit, excluding eyes if not within normal limits $[39,40]$.

The order of testing with the CVA or with charts was randomized along with the eye tested first. All vision testing was performed in the same darkened room, maintained below $3 \mathrm{~cd} / \mathrm{m}^{2}$ (except for the glare testing as noted below). Eyes with myopia or hyperopia underwent testing with a trial frame containing lenses with anti-reflective coatings and with hydrogel, PureVision contact lenses (Bausch and Lomb, Rochester NY) with a break of 30 minutes between. Prior to testing, over-refraction was performed with contact lenses to determine there was no residual astigmatism. Testing with the charts was performed as per the recommendations of the ETDRS manual [41]; the acuity was scored by total letter count (TLC) converted to logMAR [42-44].

The hypothesis that the CVA presentation in the glare modules at $10 \% \mathrm{MC}$ and $8 \% \mathrm{MC}$ mimics viewing a $15 \% \mathrm{MC}$ target against its background with the sun overhead and with the sun at $15^{\circ}$ off-axis was also tested. On a sunny day, each of the emmetropic patients was positioned such that a 15\% ETDRS chart was viewed outside, against the sky, with the sun overhead, but forward of the subject, and then the vision was measured again with the sun at $15^{\circ}$ off-axis as defined with a protractor. Testing with the $15 \% \mathrm{MC}$ chart out-of-doors was compared with the CVA testing performed at $10 \% \mathrm{MC}$ and $8 \% \mathrm{MC}$ in the darkened room.

\section{Statistical analysis}

Comparisons were made between the acuity measured with each CVA module and that measured with the logMAR chart presenting similar Michelson contrast letters, although for the mesopic modules, it should be noted that, since charts cannot be obtained with white letters against a black background, the acuity was measured utilizing gray letter charts of similar luminance and contrast but against a white background. The acuities measured with the photopic CVA modules, which presented gray letters against a white background, were compared with acuities measured with charts presenting gray letters of the same MC (Tables $2 a$ and $2 b$ ). The results for each CVA module or chart were first tested for normal, parametric distribution by Levene's Test for Equality of Variances [45]. General Estimated Equation (GEE) analysis and General Linear Models (GLM) analyses correction were performed to define the influence of including both eyes for each patient [46-48].

For each luminance and contrast environment, the mean and standard deviation were calculated for the differences of the measurements by the two methods; Pearson correlation coefficients were examined, and Bland and Altman statistics [49] calculated to examine for significant differences. Bland and Altman graphs were developed for each CVA module tested in comparison with the corresponding ETDRS chart (plotting differences versus averages of the two, example Figure 2).

To evaluate test-retest reliability of each CVA module in comparison with that of the chart of similar contrast and luminance, in 20 eyes of 20 of the subjects the CVA and chart testing were both conducted twice in the same order with a 30 minute break in between. Reliability was calculated again after the method of Bland and Altman [49].

\section{Results}

481 eyes of 241 normal subjects (Tables $2 \mathrm{a}$ and $2 \mathrm{~b}$ ) were tested with both the CVA modules (Table 1a) and with the series of logMAR charts to which they were compared (Table $1 \mathrm{~b}$ ). The mean age and range of all of the 3 refractive groups was similar as assessed by a one-way ANOVA 


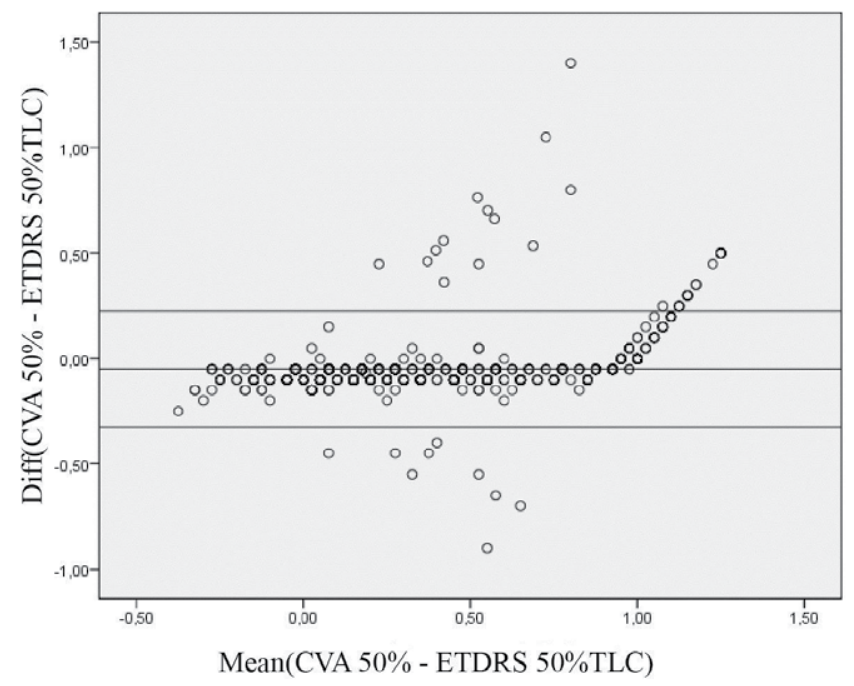

Figure 2: Bland and Altman Graph presenting the difference between logMAR acuity measured with CVA at 50\% Michelson contrast (white letter on a black background) and the visual acuity measured with the ETDRS chart of the same contrast (black letter on a white background) calculated by total letter count (TLC) plotted against the average of the two measurements. Horizontal lines represent the $95 \%$ confidence limits (logMAR). Total number of eyes measured 481 .

\begin{tabular}{|c|c|c|c|}
\hline Age groups (years) & Emmetropic eyes (\#Patients) & Myopic eyes (\#Patients) & Hyperopic eyes (\#Patients) \\
\hline $18-30$ & $56(28)$ & $44(27)$ \\
\hline $31-50$ & $56(28)$ & $54(22)$ \\
\hline $51-65$ & $50(25)$ & $53(27)$ \\
\hline Total & $162(81)$ & $151(76)$ \\
\hline
\end{tabular}

Table 2a: Arrangement of age groups is presented for the emmetropic, myopic and hyperopic eyes tested with both the CVA and ETDRS charts. Note: The myopic and hyperopic eyes were tested with best correction using both contact lenses and spectacle lenses. The one-way analysis of variance (ANOVA) is utilized to determine whether there are any significant differences between the age groups.

\begin{tabular}{|c|c|c|c|c|c|}
\hline \multicolumn{6}{|c|}{ Anova testing three age groups } \\
\hline & \multicolumn{5}{|c|}{ Samples } \\
\hline & 1 & 2 & \multicolumn{2}{|l|}{3} & Total \\
\hline $\mathrm{N}$ & 162 & 151 & \multicolumn{2}{|l|}{168} & 481 \\
\hline$-X$ & 6234 & 5831 & \multicolumn{2}{|l|}{6483} & 18548 \\
\hline -Mean & 38.4815 & 38.6159 & \multicolumn{2}{|l|}{38.5893} & 38.5613 \\
\hline$-\mathrm{X} 2$ & 269326 & 257147 & \multicolumn{2}{|l|}{284855} & 811328 \\
\hline Variance & 182.8102 & 213.1848 & \multicolumn{2}{|l|}{207.6686} & 200.1926 \\
\hline Std.Dev. & 13.5207 & 14.6008 & \multicolumn{2}{|l|}{14.4107} & 14.1489 \\
\hline Std.Err. & 1.0623 & 1.1882 & \multicolumn{2}{|l|}{1.1118} & 0.6451 \\
\hline \multicolumn{6}{|c|}{ ANOVA Summary } \\
\hline Source & SS & df & MS & $\mathrm{F}$ & $P$ \\
\hline Treatment/between groups & 16.137 & 2 & 0.8069 & 0 & 1 \\
\hline
\end{tabular}

Table 2b: Anova testing three age groups

evaluation (Tables $2 \mathrm{a}$ and $2 \mathrm{~b}$ ).

The acuity data demonstrated a normal distribution, as examined by Levene's Test for Equality of Variances for all eyes measured with each CVA module and matching chart. Among all of the eyes tested and all refractive groups, the best acuity was obtained with the $98 \%$ MC mesopic white-on-black module (averaging - $0.01 \pm 0.21 \log \mathrm{MAR}$ ) with a similar but slightly poorer acuity measured with the $98 \%$ MC module that presented black Landolt C's against the white $100 \mathrm{~cd} / \mathrm{M}^{2}$ background (+0.01 $\pm 0.19 \log$ MAR). In comparison, the two mesopic modules, the first presenting Landolt C's at $25 \% \mathrm{MC}$ against $5 \mathrm{~cd} / \mathrm{m}^{2}$ (representing restaurant dining) demonstrated a worsening of acuity to a mean of $0.44 \pm 0.34 \log \mathrm{MAR}$ and then a decline $0.37 \pm 0.42 \log \mathrm{MAR}$ when tested at $50 \% \mathrm{MC}$ at $1.6 \mathrm{~cd} / \mathrm{m}^{2}$ (representing driving at dusk). For the $10 \%$ photopic glare module (representing golf or tennis with the sun overhead) the measured mean acuity declined to $0.25 \pm 0.23$ logMAR and at $8 \% \mathrm{MC}$ (representing the same sports with the sun offaxis at 15 degrees) the mean acuity declined to $0.29 \pm 0.25 \log$ MAR.

The Pearson correlation coefficients between the acuities measured with each CVA module and the corresponding logMAR chart are presented in Table 3. The Pearson correlation coefficients were greater than 0.8 for all modules $(\mathrm{p}<0.001)$ except the $98 \%$ photopic, glare module, which was greater than $0.5(\mathrm{p}<0.001)$. Similar Pearson correlations were 
obtained for all CVA modules compared with the logMAR charts when the total group was subdivided with regard to age or refractive error.

The average difference between the two tests performed in the same patient was negative for all CVA modules (Table 4a), indicating that the CVA acuity was smaller (better) than that obtained with the similar contrast chart; however the standard deviation of the difference remained below $0.1 \log M A R$, the test-retest reliability of either test (Table $4 \mathrm{~b}$ ) indicating that the two tests are essentially similar. Figure 3 demonstrates a box and whisker plot of the differences in acuities measured with each CVA module and with the corresponding chart for all eyes; the outliers are also included and are marked with their ages, demonstrating a spread across all ages.

The sigma (standard deviation) of the differences between the acuity measured with the CVA and that measured with the corresponding chart were similar to the test-retest differences of each test confirming that the two tests are similar as suggested by Bland and Altman [49] and as confirmed by others of chart test-retest measurement $[43,44,50]$. The sigma of the acuity difference between each CVA module and the compared logMAR chart, according to Bland and Altman [49], should be corrected with the test-retest sigma for each of the tests (according to the function $=\sqrt{ } \mathrm{SD}+1 / 4 * \mathrm{SD}_{1}{ }^{2}+1 / 4 * \mathrm{SD}_{2}{ }^{2}$ ). The corrected sigma's are presented in Table $4 \mathrm{a}$, varying between 0.09 and $0.2 \log$ MAR. The mean of the test-retest difference in logMAR for each CVA module and that of the chart to which it was compared was close to 0 confirming that with both tests there was no learning effect.

When the acuity was measured with a $15 \%$ MC logMAR chart placed outdoors with the sun overhead, the vision correlated with that obtained using the $10 \%$ MC CVA black-on-white glare module tested in the darken room (Pearson correlation $\mathrm{r}=0.968, \mathrm{p}<0.001$ ). When the $15 \%$ chart was placed with the sun at $15^{\circ}$ off-axis from fixation, the vision correlated with the vision measured in the darkened room using the $8 \%$ contrast CVA module (Pearson correlation $\mathrm{r}=0.975, \mathrm{p}<0.001$ ).

\section{Discussion}

In this study, similar to others, substantial changes in central acuity were noted when tested under conditions varying in contrast and luminance. The best acuity was obtained with $98 \% \mathrm{MC}$, white letters presented against a dark background, $-0.01 \pm 0.19 \log$ MAR, with a slightly larger value in these normal eyes obtained when testing with 98\% MC black letters against a white background. The decline in acuity to $0.25 \pm 0.23 \log$ MAR at $10 \% \mathrm{MC}$ and to $0.29 \pm 0.25 \log \mathrm{MAR}$ at $8 \%$ MC gray letters against a white, glare background is similar to contrast sensitivity measurements performed previously [14]. In this study the decline in acuity under mesopic environments was even greater, measuring $0.44 \pm 0.34 \log \mathrm{MAR}$ at $25 \% \mathrm{MC}$ against a background of $5 \mathrm{~cd} / \mathrm{m}^{2}$, representing vision tasks in a dim restaurant and to $0.37 \pm$ $0.42 \log$ MAR at $50 \%$ contrast against a background of $1.6 \mathrm{~cd} / \mathrm{m}^{2}$, representing vision tasks required while driving at dusk. This decline in acuity appears similar to observations made with charts under similar mesopic conditions reported by Olsen et al. [51-53].

The acuity measurements obtained with each CVA module correlated closely with acuity measured utilizing charts that presented similar Michelson contrasts. The Pearson correlation coefficients (Table 3) were greater than 0.8 in all modules except for the $95 \%$ photopic/ glare module, which was greater than 0.5 . We believe the correlation coefficient recorded for this module was reduced because, in the testing sequence, it appeared immediately after the mesopic testing when the eye was relatively dark adapted and then presented with the high glare monitor background. Nevertheless, the correlation for this module, as with the others, was still very significant $(\mathrm{p}<0.001)$.

For 5 of the 6 modules the sigma of the difference between the acuity measured with the CVA and that measured with the similar contrast and luminance logMAR chart ranged between 0.07 logMAR and $0.13 \operatorname{logMAR}$, similar to the sigma of test-retest differences measured with all CVA modules and charts measured among these subjects (Table 4a), usually lying between 0.05 and $0.12 \operatorname{logMAR}$, and similar to test-retest reliability measurements previously reported for TLC measurements with ETDRS high contrast charts among normal young subjects (typically a sigma of 0.07 to $0.09 \log$ MAR $[42,43,50,54$ 56]). The only sigma of the difference between CVA and chart tests that was greater was for the high contrast photopic CVA module when compared with the photopic high contrast chart testing (sigma of $0.2 \log$ MAR), which again was most probably due to this module appearing in sequence immediately after the mesopic testing. The mean

\begin{tabular}{|c|c|c|c|c|c|c|}
\hline & Number of comparisons & ETDRS $97 \%$ & ETDRS 25\% & ETDRS $50 \%$ & ETDRS $10 \%$ & ETDRS 8\% \\
\hline & & \multicolumn{5}{|c|}{ Pearson correlation coefficient (significance) } \\
\hline CVA98\% Mes. & 481 & $0.88(p<0.01)$ & & & & \\
\hline CVA25\% Mes. & 481 & & $0.94(p<0.01)$ & & & \\
\hline CVA50\% Mes. & 481 & & & $0.93(p<0.01)$ & & \\
\hline CVA 98\% Pho. & 481 & $0.51(p<0.01)$ & & & & \\
\hline CVA10\% Glare & 481 & & & & $0.94(p<0.01)$ & \\
\hline CVA 8\% Glare & 481 & & & & & $0.93(p<0.01)$ \\
\hline
\end{tabular}

Table 3: Pearson correlation coefficients are presented between the acuity measured with each CVA module and that measured with the respective chart presenting similar luminance and contrasting letters; the MC=Michelson Contrast

\begin{tabular}{|c|c|c|c|c|c|}
\hline & Mean diff of tests & $\begin{array}{c}\text { Sigma diff of CVA and } \\
\text { ETDRS }\end{array}$ & $\begin{array}{l}\text { Sigma diff CVA test- } \\
\text { retest }\end{array}$ & $\begin{array}{c}\text { Sigma diff ETDRS test- } \\
\text { retest }\end{array}$ & $\begin{array}{c}\text { Corrected Sigma of test } \\
\text { differences }\end{array}$ \\
\hline Mesopic CVA - ETDRS 98/7\% & -0.08 & 0.09 & 0.12 & 0.06 & 0.11 \\
\hline Mesopic CVA - ETDRS 50\% & -0.06 & 0.1 & 0.09 & 0.1 & 0.12 \\
\hline Mesopic CVA - ETDRS 25\% & -0.04 & 0.13 & 0.05 & 0.11 & 0.15 \\
\hline Photopic CVA - ETDRS 98/7\% & -0.09 & 0.2 & 0.09 & 0.06 & 0.20 \\
\hline Photopic CVA - ETDRS 10\% & -0.07 & 0.07 & 0.12 & 0.04 & 0.10 \\
\hline Photopic CVA - ETDRS 8\% & -0.06 & 0.09 & 0.05 & 0.04 & 0.09 \\
\hline
\end{tabular}

Table 4a: Mean and sigma (+/- 1SD) of the Differences between the CVA module and chart testing are presented along with the Reliability Test-retest Sigma of CVA and chart testing. ${ }^{*}$ Corrected Sigma is the sigma that is corrected according to Bland and Altman in which the sigma of the difference (logMAR) of the two tests is modified by the measured sigmas of test-retest differences for each of each test $\left(=\sqrt{ } \mathrm{SD}+1 / 4{ }^{*} \mathrm{SD} 1^{2}+1 / 4 * \mathrm{SD} 2^{2}\right)$ 


\begin{tabular}{|c|c|c|c|c|c|c|}
\hline & ETDRS $97 \%$ & ETDRS 25\% & ETDRS $50 \%$ & ETDRS $10 \%$ & ETDRS 8\% & \\
\hline Avg & -0.03 & 0.04 & 0.1 & 0.02 & 0.01 & \\
\hline Std. dev. & 0.05 & 0.07 & 0.05 & 0.02 & 0.02 & \\
\hline \multirow[t]{2}{*}{$95 \% \mathrm{Cl}$} & 0.11 & 0.14 & 0.1 & 0.05 & 0.09 & \\
\hline & $\begin{array}{c}\text { CVA 98\% } \\
\text { Mes. }\end{array}$ & CVA $25 \%$ Mes. & CVA $50 \%$ Mes. & CVA $10 \%$ Glare & CVA 8\% Glare & CVA 98\% Pho \\
\hline Avg & -0.06 & 0.02 & 0.02 & -0.02 & 0.07 & -0.03 \\
\hline Std. dev. & 0.06 & 0.04 & 0.06 & 0.04 & 0.03 & 0.04 \\
\hline $95 \% \mathrm{Cl}$ & 0.13 & 0.09 & 0.11 & 0.08 & 0.07 & 0.08 \\
\hline
\end{tabular}

Table 4b: Mean, standard deviation and 95\% confidence interval for test-retest of ETDRS charts and CVA modules presenting similar Michelson contrasts.

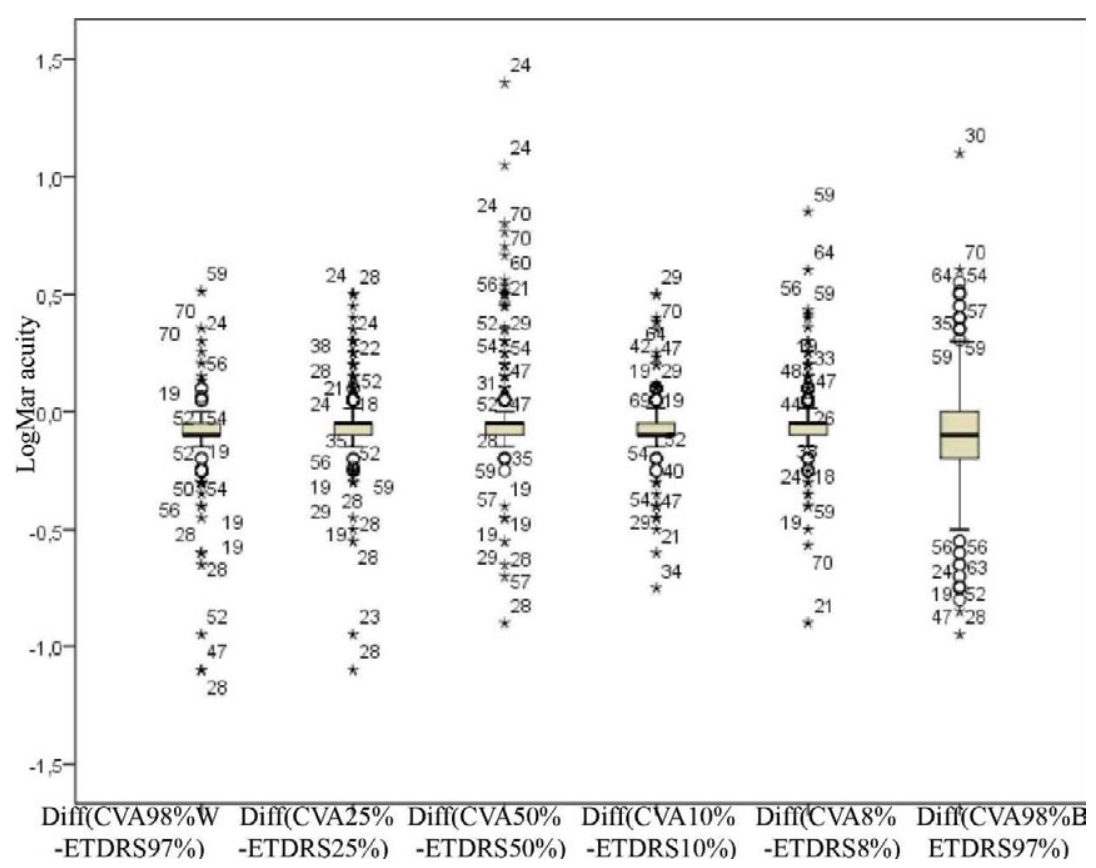

Figure 3: Box and whisker plot of the difference in logMAR acuity between each CVA module and the ETDRS chart (scored by total letter count) presenting the same Michelson Contrast. The plot depicts the median, $25 \%$, and $75 \%$ quartiles; the whiskers represent $95 \%$ confidence limits. The outliers are marked with asterisks for those beyond $1.5 \times$ the box length and with stars for those beyond $3.0 \times$ box length. Each of the outliers is presented with the patient's age.

of the test-retest differences for each CVA module as well as testing with the chart was close to zero (Table 4a) confirming that with both tests there was minimal learning among the patients studied.

As explained previously, the CVA mesopic modules presented a background luminance that was different from the background luminance of the $\operatorname{logMAR}$ chart to which the acuity measurement was compared, with the CVA module presenting brighter letters than the background whereas the chart presented letters darker than the background but matched for the luminance of the letter and for the absolute Rayleigh-Michelson contrast. Prior studies have examined the change in acuity when the letter and background luminance were reversed (with similar contrast but reversed polarity) [30-32]; although the bright letter against the dark background resulted in an improved acuity in those studies, the difference observed for subjects of similar age as in this study was similar to the differences noted here.

When the outliers were examined (outside of the $95 \%$ confidence limits of the difference between the acuities), a predominance of olderaged subjects was anticipated as had been noted in prior studies $[28,29]$ due presumably to increased intraocular light scatter. However, in this study the outliers were spread among all ages of these normal subjects
(Figure 3). In addition among the outliers, both cases of worse chart or worse CVA acuity were observed (Figure 3).

Among the three photopic glare CVA modules, a slightly better acuity of 0.05 to $0.08 \operatorname{logMAR}$ was measured with the CVA than that measured with the logMAR chart, even though the CVA presentation time was limited to $250 \mathrm{msec}$ compared with 1 to 4 seconds often taken to scrutinize a letter on a chart. The reason for the better acuity obtained with the CVA modules is unclear but may be due to the slightly higher background luminance of the CVA monitor compared with that of the letter charts. However, the difference in acuity was less than 0.08 logMAR in all cases, less than the test-retest reliability for both CVA and chart testing and compares with differences in acuity measured in prior studies when the Rayleigh-Michelson contrast was held constant but changes in the background luminance were introduced that were similar to those of this study [56-58].

In this study, the visual acuity measured with the $10 \%$ and $8 \%$ glare modules closely paralleled the $15 \%$ contrast letter chart placed in the sunlit conditions, in the first case with the $15 \%$ chart placed such that the sun was overhead, but forward of the subject and in the second with the sun at $15^{\circ}$ off-axis from fixation. This supports the prior work of Vos 
[36] that the alterations of vision in such environments with veiling glare are dependent upon the relative severity of the glare and its position offaxis and indicates that a test of visual performance under daylight glare can be conducted in a darkened room using such a computer monitor by reducing the contrast appropriately. In this validation study the pupil sizes were not carefully measured or controlled, but none-the-less, the correlations remained high with small Bland and Altman differences. Other studies have examined the changes in acuity measured with the CVA in eyes with various media opacities or following cataract surgery [24,25] and in eyes with macular pathology [25-27].

It may be criticized that in this study both eyes of the subjects were utilized, but in all a significant number of eyes were tested (481) and GEE and GLM analyses demonstrated no significant influence of utilizing both eyes of an individual. In the GLM model analysis (logistic regression) binary response variables included subject and time as covariates while the analogous GEE model takes into account correlation between measurements at multiple time points.

\section{Conclusion}

This study has demonstrated that the new CVA interactive program produces visual acuities under an assortment of lighting and contrast conditions that are very similar to acuities measured using letter charts with the same contrast placed in similar lighting conditions when testing is conducted in normal eyes under the age conditions examined. The advantage of the CVA is that, unlike the chart, logMAR 0.05 steps in letter size can easily be implemented to improve the sensitivity of the test as recommended by Rosser [42] and several environmental conditions can be tested in a short testing period of about 2-3 minutes for both eyes, within the time constraints of the busy clinic. Therefore the CVA should allow the examiner to better understand the performance of a patient's vision under a number of environments that are encountered during routine day and evening activities. Testretest differences are small, indicating minimal learning and are similar for both the CVA and chart testing in the normal population studied validating the testing methodology of the CVA. If the validation were to be conducted in eyes, for example with macular pathology, we would not expect such a similarity, since in such eyes the patient often reads the chart extremely slowly and omits letters because of axial and paraxial scotomata that require them to search until the better functioning portions of the visual field are overlaid on the individual chart letters. For such eyes, we believe the acuity obtained with the CVA will portray a better relationship with real world vision task performance than that obtained with chart testing.

\section{References}

1. Bradley A, Thomas T, Kalaher M, Hoerres M (1991) Effects of spherical and astigmatic defocus on acuity and contrast sensitivity: a comparison of three clinical charts. Optom Vis Sci 68: 418-426.

2. Pesudovs K, Hazel CA, Doran RM, Elliott DB (2004) The usefulness of Vistech and FACT contrast sensitivity charts for cataract and refractive surgery outcomes research. Br J Ophthalmol 88: 11-16.

3. Kwon M, Legge GE (2012) Spatial-frequency requirements for reading revisited. Vision Res 62: 139-147.

4. Legge G, Rubin G, Pelli D, Schleske M (1985) Psychophysics of reading II: Low vision. Vision Research 25: 253-266.

5. Legge GE, Ross JA, Luebker A, LaMay JM (1989) Psychophysics of reading VIII. The Minnesota Low-Vision Reading Test. Optom Vis Sci 66: 843-853.

6. Legge GE, Ross JA, Isenberg LM, LaMay JM (1992) Psychophysics of reading. Clinical predictors of low-vision reading speed. Invest Ophthalmol Vis Sci 33 : 677-687.
7. Burg A (1964) An investigation of some relationships between dynamic visua acuity, static visual acuity and driving record. Los Angeles: UCLA Department of Engineering, Report, pp. 64-18.

8. Haegerstrom-Portnoy G, Brabyn J, Schneck ME, Jampolsky A (1997) The SKILL Card. An acuity test of reduced luminance and contrast. Smith-Kettlewell Institute Low Luminance. Invest Ophthalmol Vis Sci 38: 207-218.

9. Rubin G (1988) Reliability and sensitivity of clinical contrast sensitivity test. Clin Vision Sci 2: 167-177.

10. Jones HS, Moseley MJ, Thompson JR (1994) Reliability of the Cambridge Low Contrast Gratings. Ophthalmic Physiol Opt 14: 287-289.

11. Zheng X, Mondloch CJ, Segalowitz SJ (2012) The timing of individual face recognition in the brain. Neuropsychologia 50: 1451-1461.

12. Rao RPN, Ballard DH (1995) Natural basis functions and topographic memory for face recognition. In: Proceedings of the International Joint Conference on Artificial Intelligence (IJCAI 95), page 10-19.

13. Bruce V, Hancock P, Mike AB (1998) Human face perception and identification. Face Recognition 163: 51-72.

14. Pentland A, Moghaddam B, Starner T (1994) View-based and modular eigenspaces for face recognition. Proceedings of the International Conference on Computer Vision and Pattern Recognition. Seattle, WA, 21-23 June, pp. 84-91.

15. Bullimore MA, Bailey IL (1995) Reading and eye movements in age-related maculopathy. Optom Vis Sci 72: 125-138.

16. Elliott DB, Bullimore MA, Patla AE, Whitaker D (1996) Effect of a cataract simulation on clinical and real world vision. $\mathrm{Br} \mathrm{J}$ Ophthalmol 80: 799-804.

17. Brown B, Zadnik K, Bailey IL, Colenbrander A (1984) Effect of luminance, contrast, and eccentricity on visual acuity in senile macular degeneration. Am J Optom Physiol Opt 61: 265-270.

18. Sloane ME, Owsley C, Alvarez SL (1988) Aging, senile miosis and spatial contrast sensitivity at low luminance. Vision Res 28: 1235-1246.

19. Sloane ME, Owsley C, Jackson CA (1988) Aging and luminance-adaptation effects on spatial contrast sensitivity. J Opt Soc Am A 5: 2181-2190.

20. Adams AJ, Wong LS, Wong L, Gould B (1988) Visual acuity changes with age: some new perspectives. Am J Optom Physiol Opt 65: 403-406.

21. Sloan LL (1969) Variation of acuity with luminance in ocular diseases and anomalies. Doc Ophthalmol 26: 384-393.

22. Bach M (1996) The Freiburg Visual Acuity test--automatic measurement of visual acuity. Optom Vis Sci 73: 49-53.

23. Ehrenstein WH, Ehrenstein A (1999) Psychophysical Methods. In: Modern Techniques in Neuroscience Research.

24. Gomez ML (2014) Measuring the quality of vision after cataract surgery. Curr Opin Ophthalmol 25: 3-11.

25. Sloan LL (1969) Variation of acuity with luminance in ocular diseases and anomalies. Doc Ophthalmol 26: 384-393.

26. Barteselli G, Gomez M, Doede A, Chhablani J, Gutstein W, et al. (2014) Visua function assessment in simulated real-life situations in patients with age-related macular degeneration compared to normal subjects. Eye: 1-8.

27. Barteselli G, Chhablani J, Gomez M, Doede A, Dustin L, Kozak I, et al. (2014) Visual function assessment in simulated real-life situations in HIV-infected subjects. Plos one 9: e97203.

28. Anderson R, Coulter E, Zlatkova M, Demirel S (2003) Short-wavelength acuity: optical factors affecting detection and resolution of blue-yellow sinusoida gratings in foveal and peripheral vision. Vision Res 43: 101-107.

29. Johnson CA, Casson EJ (1995) Effects of luminance, contrast, and blur on visual acuity. Optom Vis Sci 72: 864-869.

30. Westheimer G (2003) Visual acuity with reversed-contrast charts: I. Theoretica and psychophysical investigations. Optom Vis Sci 80: 745-748.

31. Westheimer G, Chu P, Huang W, Tran T, Dister R (2003) Visual acuity with reversed-contrast charts: II. Clinical investigation. Optom Vis Sci 80: 749-752.

32. Johnson CA (2008) Occupational psychophysics to establish vision requirements. Optom Vis Sci 85: 910-923. 
Citation: Gutstein W, Sinclair SH, Presti P, North RV (2015) Interactive Thresholding of Central Acuity under Contrast and Luminance Conditions Mimicking Real World Environments: 1. Evaluation against LogMAR Charts. J Comput Sci Syst Biol 8: 225-232. doi:10.4172/jcsb.1000193

33. Luo MR, Cui G, Rigg B (2001) The development of the CIE 2000 colordifference formula: CIEDE2000. Color research and application 26: 340-350.

34. Reinhard E, Khan E, Ahmet Oguz A, Johnson G (2007) Color Imaging, Fundamentals and Applications. Wellesley, A K Peters, Ltd 1-1074.

35. Peli E (1990) Contrast in complex images. J Opt Soc Am A 7: 2032-2040.

36. Vos JJ (2003) On the cause of disability glare and its dependence on glare angle, age and ocular pigmentation. Clin Exp Optom 86: 363-370.

37. Ferris FL, Sperduto RD (1982) Standardized illumination for visual acuity testing in clinical research. Am J Ophthalmol 94: 97-98.

38. Chylack LT Jr, Wolfe JK, Singer DM, Leske MC, Bullimore MA, et al. (1993) The Lens Opacities Classification System III. The Longitudinal Study of Cataract Study Group. Arch Ophthalmol 111: 831-836

39. Cho P, Brown B, Chan I, Conway R, Yap M (1992) Reliability of the tear breakup time technique of assessing tear stability and the locations of the tear breakup in Hong Kong Chinese. Optom Vis Sci 69: 879-885.

40. Timberlake GT, Doane MG, Bertera JH (1992) Short-term, low-contrast visual acuity reduction associated with in vivo contact lens drying. Optom Vis Sci 69 : 755-760

41. (1980) Recommended stardard procedures for the clinical measurement and specification of visual acuity. Report of working group 39. Committee on vision. Assembly of Behavioral and Social Sciences, National Research Council, National Academy of Sciences, Washington, D.C. Adv Ophthalmol 41: 103-148.

42. Rosser DA, Cousens SN, Murdoch IE, Fitzke FW, Laidlaw DA (2003) How sensitive to clinical change are ETDRS logMAR visual acuity measurements? Invest Ophthalmol Vis Sci 44: 3278-3281.

43. Arditi A, Cagenello R (1993) On the statistical reliability of letter-chart visual acuity measurements. Invest Ophthalmol Vis Sci 34: 120-129.

44. Hazel CA, Elliott DB (2002) The dependency of logMAR visual acuity measurements on chart design and scoring rule. Optom Vis Sci 79: 788-792.

45. Levene H (1960) Contributions to Probability and Statistics: Essays in Honor of Harold Hotelling. Journal of the American Statistical Association 57: 205-207.
46. Horton JN, Lipsitz SR (1999) Review of Software to Fit Generalized Estimating Equation Regression Models. The American Statistician 53: 160-169.

47. Murdoch IE, Morris SS, Cousens SN (1998) People and eyes: statistical approaches in ophthalmology. $\mathrm{Br} \mathrm{J}$ Ophthalmol 82: 971-973.

48. Ray WA, O'Day DM (1985) Statistical analysis of multi-eye data in ophthalmic research. Invest Ophthalmol Vis Sci 26: 1186-1188.

49. Bland JM, Altman DG (1986) Statistical methods for assessing agreement between two methods of clinical measurement. The Lancet 1: 307-310.

50. Bosch ME, Wall M (1997) Visual acuity scored by the letter-by-letter or probit methods has lower retest variability than the line assignment method. Eye (Lond) 11: 411-417.

51. Olson PL, Aoki T (1989) The measurement of dark adaptation levels in the presence of glare (Report No. UMTRI 89-34). Ann Arbor, MI: University of Michigan Transportation Research Institute.

52. Richards OW (1977) Effects of luminance and contrast on visual acuity, ages 16 to 90 years. Am J Optom Physiol Opt 54: 178-184.

53. Pesudovs K, Marsack JD, Donnelly WJ, Thibos LN, Appelgate RA (2004) Measuring visual acuity - mesopic or photopic conditions, and high or low contrast letters? J Refract Surg 20: S508-14.

54. Elliott DB, Sheridan M (1988) The use of accurate visual acuity measurements in clinical anti-cataract formulation trials. Ophthalmic Physiol Opt 8: 397-401.

55. Lovie-Kitchin JE, Brown B (2000) Repeatability and intercorrelations of standard vision tests as a function of age. Optom Vis Sci 77: 412-420.

56. Newacheck JS, Haegerstrom-Portnoy G, Adams AJ (1990) Predicting visua acuity from detection thresholds. Optom Vis Sci 67: 184-191.

57. Adams AJ, Wong LS, Wong L, Gould B (1988) Visual acuity changes with age: some new perspectives. Am J Optom Physiol Opt 65: 403-406.

58. Ikeda K, Noda K, Yamaguchi S (1983) Visual acuity as a function of luminance contrast of landolt rings and adaptation luminance. Journal of light and visual environment 7: 28-36. 